\title{
$475{ }^{\circ} \mathrm{C}$ Embrittlement in a Duplex Stainless Steel UNS S31803
}

\author{
S.S.M. Tavares ${ }^{\mathrm{a}}$, R.F. de Noronha ${ }^{\mathrm{a}}$,M.R. da Silva ${ }^{\mathrm{b}}$, J.M. Neto ${ }^{\mathrm{c}}$, S. Pairis ${ }^{\mathrm{d}}$ \\ ${ }^{\mathrm{a}}$ Universidade Federal Fluminense, Departamento de Engenharia Mecânica, \\ Rua Passo da Pátria, 156 - 24210-470 Niteroi - RJ, Brasil \\ ${ }^{\mathrm{b}}$ Escola Federal de Engenharia de Itajubá \\ ${ }^{\mathrm{c} I n s t i t u t o}$ de Física, Universidade Federal do Rio de Janeiro, \\ Rio de Janeiro - RJ, Brasil \\ ${ }^{\mathrm{d}}$ Laboratoire de Cristallographie, CNRS, Grenoble, France
}

Received: November 14, 2000; Revised: September 22, 2001

\begin{abstract}
The susceptibility of a duplex stainless steel UNS S31803 to thermal embrittlement at $475{ }^{\circ} \mathrm{C}$ was evaluated by means of mechanical tests (impact energy and hardness), magnetic measurements (hysteresis and thermomagnetic analysis) and scanning electron microscopy. The results show that the material undergoes severe embrittlement and hardening in the first $100 \mathrm{~h}$. The corrosion resistance of the ferrite phase in a $10 \% \mathrm{HNO}_{3}+0.05 \% \mathrm{HF}$ solution deteriorated after $500 \mathrm{~h}$ of ageing. The Curie temperature $\left(\mathrm{T}_{\mathrm{c}}\right)$ was the most sensitive magnetic property to the microstructural changes that promote embrittlement. $T_{\mathcal{C}}$ increases with ageing time due to the progressive reduction of chromium in the Fe-rich matrix during spinodal decomposition.
\end{abstract}

Keywords: duplex stainless steel, $475^{\circ} \mathrm{C}$ embrittlement

\section{Introduction}

Duplex stainless steels (DSS) are widely used in chemical, petrochemical, cellulose and nuclear plants around the world ${ }^{1-4}$. Because of their fine austenitic-ferritic microstructure they offer an excellent combination of mechanical and corrosion resistance properties.

The best performance of wrought DSS is obtained in the solution treated condition. Nevertheless, two hardening and embrittlement processes may occur when these materials are heated: (a) sigma phase $(\sigma)$ precipitation in the range of $700{ }^{\circ} \mathrm{C}$ to $900{ }^{\circ} \mathrm{C}$ and (b) precipitation of a $\mathrm{Cr}$-rich phase $\left(\alpha^{\prime}\right)$ in the range of $300{ }^{\circ} \mathrm{C}$ to $600{ }^{\circ} \mathrm{C}$. The $\alpha$ ' precipitation leads to a progressive hardening and reduction of the material toughness ${ }^{5-7}$. This precipitation occurs by spinodal decomposition, a mechanism by which the ferrite phase decomposes into a Cr-rich phase $\left(\alpha^{\prime}\right)$ and a $\mathrm{Fe}$-rich phase. Because this reaction occurs more rapidly at $475{ }^{\circ} \mathrm{C}$, this process is also known as " $475^{\circ} \mathrm{C}$ embrittlement". However this phase separation may also occur in temperatures as low as $300{ }^{\circ} \mathrm{C}$ in exposures after thousands of hours or at $600{ }^{\circ} \mathrm{C}$ in exposures for few minutes 8 , depending on the chemical composition of the steel.

Many researchers have studied and developed methods of detection and also quantification of thermal embrittle-

*e-mail: ssmtavares@ig.com.br Trabalho apresentado no $14^{\circ} \mathrm{CBECIMAT}$, Águas de São Pedro, Dezembro de 2000 ment in DSS. Tsuchiya et al. $^{9}$ and Evanson et al. ${ }^{10}$ employed magnetic measurements and found that the hysteresis loss, residual induction and coercive force increased with ageing time in cast DSS. Controversially, Maeda et $a l .{ }^{7}$ have found experimentally that there is a decrease in the coercive force during the ageing of cast duplex stainless steels in the range of $350-450{ }^{\circ} \mathrm{C}$. Kim et al. ${ }^{11}$ found an increase of the Curie temperature in ferritic stainless steels aged at $370{ }^{\circ} \mathrm{C}$ and $400{ }^{\circ} \mathrm{C}$.

Another consequence of the spinodal decomposition of the ferrite phase is loss of corrosion resistance. If the $\mathrm{Cr}$ content of the Fe-rich matrix becomes lower than 14 at.\%, pits of corrosion may be observed by scanning electron microscopy (SEM) in the ferritic regions in samples etched with a $10 \% \mathrm{HNO}_{3}+0.05 \% \mathrm{HF}$ solution ${ }^{9}$.

In the present research work, the susceptibility of a DSS S31803 to thermal embrittlement at $475^{\circ} \mathrm{C}$ was evaluated by means of hardness and Charpy impact tests, magnetic measurements and SEM.

\section{Materials and Methods}

A $3 \mathrm{~mm}$ sheet of duplex stainless steel UNS S31803, with the composition shown in Table 1, was received in the solution treated condition, containing (43 \pm 3$) \%$ of 
Table 1. Chemical analysis of the material (wt $\%)$.

\begin{tabular}{lccccccc}
\hline$\% \mathrm{C}$ & $\% \mathrm{Cr}$ & $\% \mathrm{Ni}$ & $\% \mathrm{Mo}$ & $\% \mathrm{~N}$ & $\% \mathrm{~S}$ & $\% \mathrm{P}$ & $\% \mathrm{Fe}$ \\
0.032 & 22.38 & 5.32 & 2.55 & 0.1123 & 0.003 & 0.028 & balance \\
\hline
\end{tabular}

austenite phase. The material was heat treated at $475{ }^{\circ} \mathrm{C}$ for 20, 100, 300 and $500 \mathrm{~h}$.

The age hardening was measured by Brinnel hardness tests. The embrittlement was measured by Charpy tests, using subsize $(2,5 \mathrm{~mm}) \mathrm{V}$-notch specimens ${ }^{12}$. The impact tests were conducted on a universal impact machine. The aged samples were etched with a $10 \% \mathrm{HNO}_{3}+0.05 \% \mathrm{HF}$ solution and observed by SEM.

The magnetic measurements (hysteresis and thermomagnetic analysis - TMA) were carried out in a Vibrating Sample Magnetometer (VSM) EGG PAR model 4500. The TMA data were obtained with a high-temperature oven in low vacuum atmosphere $(0.1 \mathrm{mmHg})$ and under an applied magnetic field of 500 Oe. The heating rate was $5^{\circ} \mathrm{C} / \mathrm{min}$. A barium ferrite was taken as standard for magnetic measurements.

The samples for magnetic measurements were discshaped with a diameter of about $3.5 \mathrm{~mm}$ and thickness between 0.05 and $0.20 \mathrm{~mm}$. The obtained hysteresis curves were corrected for the demagnetization field as proposed by Chikazumi ${ }^{13}$ and Cullity ${ }^{14}$.

\section{Results and Discussion}

Figure 1 shows the hardness and impact energy behaviour with ageing time at $475{ }^{\circ} \mathrm{C}$. The $\alpha$ ' precipitation promotes strong hardening and embrittlement in the first $100 \mathrm{~h}$ of ageing. Figure 2 show the backscattered electrons image of the sample aged for $500 \mathrm{~h}$ and etched in a $10 \% \mathrm{HNO}_{3}+0.05 \% \mathrm{HF}$ solution. The pits observed in the ferrite phase indicate that in this condition the $\mathrm{Cr}$ content of the matrix is probably lower than 14 at $\%$. Even though a decrease of toughness had been detected in the first $20 \mathrm{~h}$ of ageing, it was only after $500 \mathrm{~h}$ of ageing that a pronounced decrease of corrosion resistance of the ferrite phase was observed by SEM. This fact show that some chemical and electrochemical tests ${ }^{15,16}$, based in the loss of corrosion resistance, may not be effective in predicting the embrittlement of the steel.

Table 2 shows the magnetic properties of coercive force $\left({ }_{\mathrm{M}} \mathrm{H}_{\mathrm{c}}\right)$, residual induction $\left(\mathrm{B}_{\mathrm{r}}\right)$ and saturation induction $\left(\mathrm{B}_{\mathrm{s}}\right)$ obtained at room temperature in the different investigated conditions. As can be seen, $\mathrm{B}_{\mathrm{r}}$ and $\mathrm{B}_{\mathrm{s}}$ were not affected by ageing and the ${ }_{\mathrm{M}} \mathrm{H}_{\mathrm{c}}$ increased very slightly with ageing time. The difference between the coercive force of the sample aged by $500 \mathrm{~h}$ and the unaged sample was about $6 \%$, which is very low if we consider the strong variation of mechanical properties that takes place in the same time.
Besides, Fig. 3 shows that the hysteresis loops of the unaged sample and the one aged for $500 \mathrm{~h}$ are almost coincident. These results are in disagreement with those obtained by Tsuchiya et al. ${ }^{9}$ and Evanson et al. ${ }^{10}$ for cast duplex stainless steels. The former authors found a great

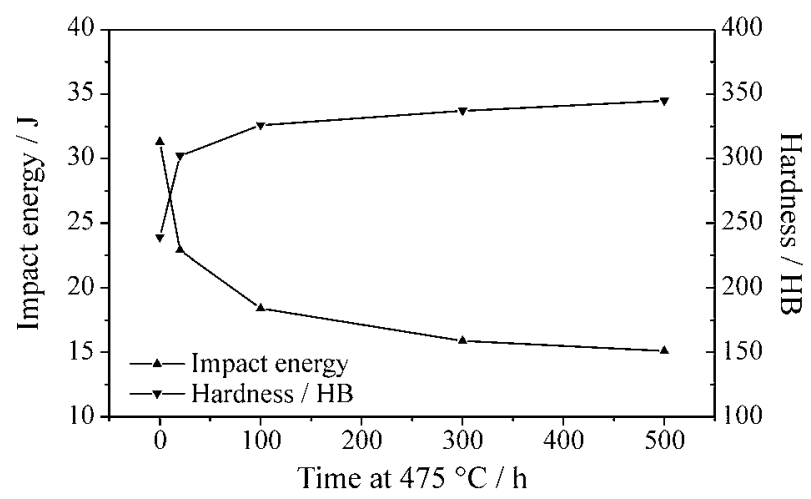

Figure 1. Impact Energy and Brinell Hardness as function of time exposure at $475^{\circ} \mathrm{C}$. $(\mathrm{ST}=$ Solution treated $)$.

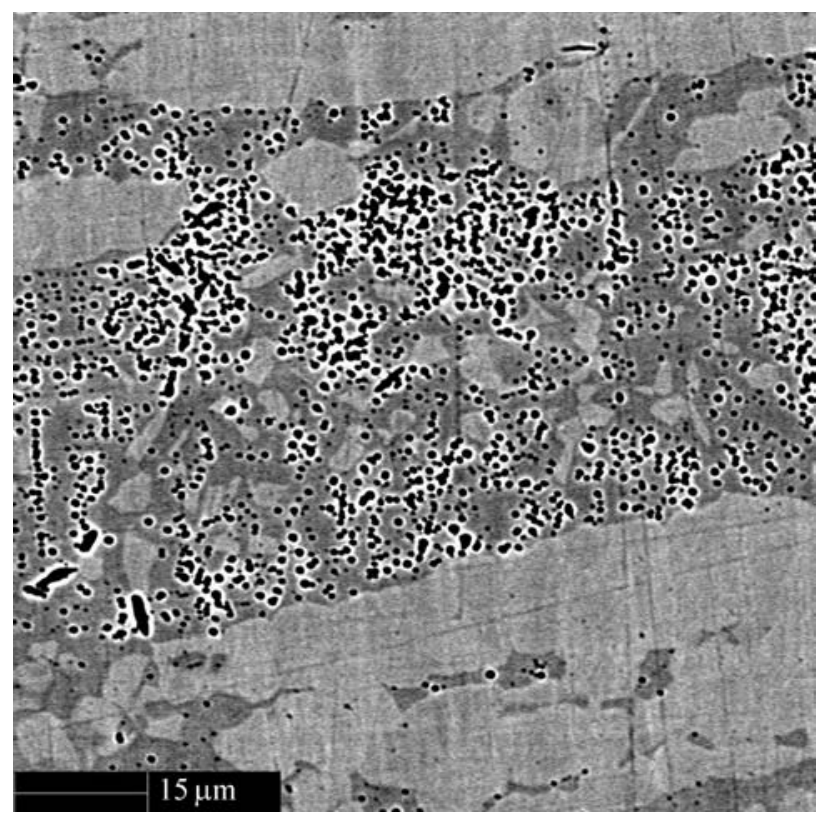

Figure 2. SEM composition image of the sample aged for $500 \mathrm{~h}$ at $475^{\circ} \mathrm{C}$, etched with $10 \% \mathrm{HNO}_{3}+0.05 \% \mathrm{HF}$ solution.

Table 2. Magnetic Properties: coercivity $\left(\mathrm{MH}_{\mathrm{c}}\right)$, residual induction $\left(\mathrm{B}_{\mathrm{r}}\right)$, saturation induction $\left(\mathrm{B}_{\mathrm{s}}\right)$ and magnetic transition temperature $\left(\mathrm{T}_{\mathrm{c}}\right)$.

\begin{tabular}{lcccc}
\hline Condition & $\mathrm{MH}_{\mathrm{c}}(\mathrm{Oe})$ & $\mathrm{B}_{\mathrm{r}}(\mathrm{G})$ & $\mathrm{B}_{\mathrm{s}}(\mathrm{G})$ & $\mathrm{T}_{\mathrm{c}}\left({ }^{\circ} \mathrm{C}\right)$ \\
\hline Solution treated & 266 & 6590 & 7535 & 503 \\
$475^{\circ} \mathrm{C} / 20 \mathrm{~h}$ & 270 & 6800 & 7500 & 533 \\
$475^{\circ} \mathrm{C} / 100 \mathrm{~h}$ & 271 & 6776 & 7554 & 550 \\
$475^{\circ} \mathrm{C} / 300 \mathrm{~h}$ & 271 & 6740 & 7575 & 558 \\
$475^{\circ} \mathrm{C} / 500 \mathrm{~h}$ & 281 & 6882 & 7362 & 566 \\
\hline
\end{tabular}




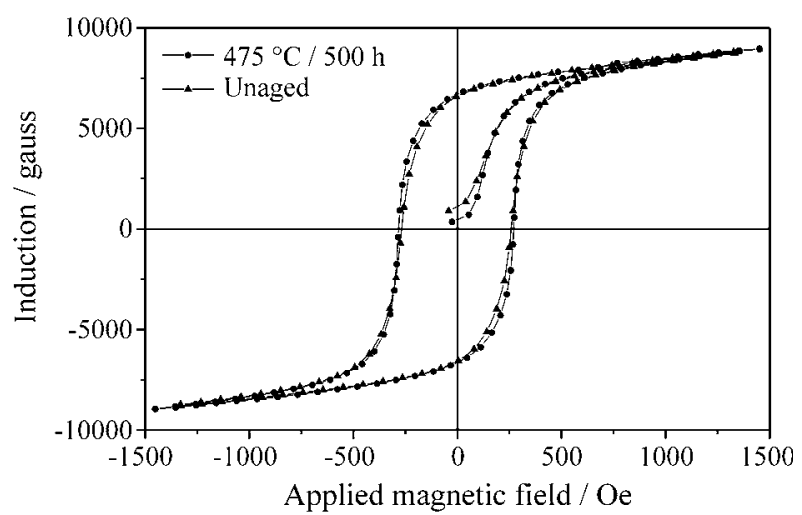

Figure 3. Comparison of the hysteresis loops of the samples solution treated and aged at $475^{\circ} \mathrm{C}$ for $500 \mathrm{~h}$.

change in the hysteresis loop due to ageing at $475{ }^{\circ} \mathrm{C}$ for $443 \mathrm{~h}$ and the latter have reported an increase in the $\mathrm{B}_{\mathrm{r}}$ values with ageing time. Its worth mentioning that in the present work, a wrought alloy was analized, while the authors cited above studied cast DSS, which contain phase proportions and chemical compositions different from wrought alloys. The steel analysed by Tsuchiya et al. ${ }^{9}$ contained only $12.5 \%$ of ferrite phase and the steels analysed by Evanson et al. ${ }^{10}$ contained 12.5 to $26.1 \%$ of this phase. These two aspects, of differences in phase proportions and chemical composition, explain the discrepancies in the of B-H curves encountered in this work, when compared with the results of the other two articles.

The output of the thermomagnetic analysis (TMA) is a curve of magnetization versus temperature. Figure 4 shows the TMA heating curves obtained for each sample. As can be seen, the magnetic transition temperature (Curie temperature $-T_{c}$ ) increases with ageing time. A precise determination of the $\mathrm{T}_{\mathrm{c}}$ can be obtained by deriving the $\mathrm{M}(\mathrm{T}) v s$. $\mathrm{T}$ curve, as shown in Fig. 5. Table 2 shows the $T_{c}$ values obtained by this procedure.

The increase of $\mathrm{T}_{\mathrm{c}}$ with ageing time at $475{ }^{\circ} \mathrm{C}$ is due to the influence of the chromium in the magnetic transition

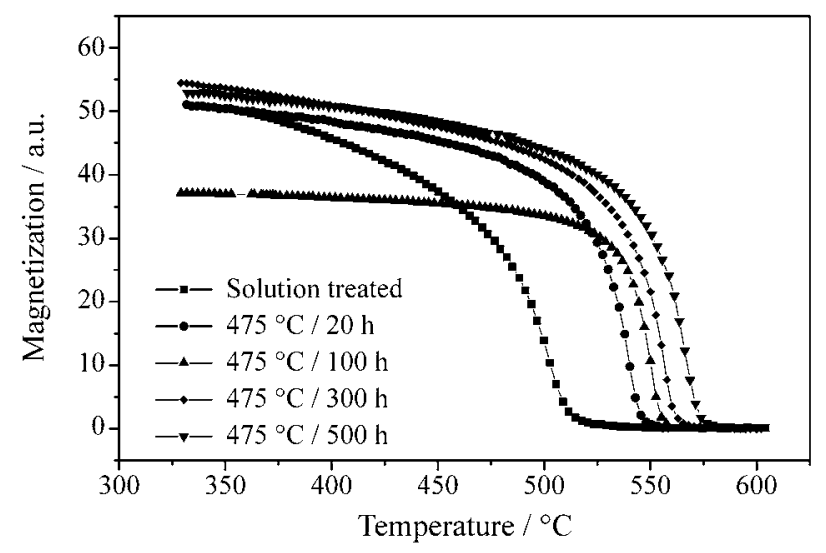

Figure 4. TMA comparative curves at increasing temperatures. temperature of ferrite. As shown in the $\mathrm{Fe}-\mathrm{Cr}$ phase diagrams available in the literature ${ }^{17-18}$, when the amount of $\mathrm{Cr}$ is higher than $3 \mathrm{wt} . \%, \mathrm{~T}_{\mathrm{c}}$ is an inverse function of the chromium content. On the other hand, the chromium content in the Fe-rich phase is progressively reduced during the ferrite decomposition. As a consequence, $T_{c}$ increases with ageing time, which is in agreement with the results obtained by Kim et al. ${ }^{11}$ in a ferritic alloy. However, no published work on the $\mathrm{T}_{\mathrm{c}}$ behaviour in DSS during the ageing embrittlement was found by the authors.

The plot of $T_{c}$ against ageing time (Fig. 6) exhibits a behaviour similar to the hardness variation (see Fig. 1). In Fig. 7 the impact energy and the Brinnel hardness are plotted against $T_{c} / T_{0}$, where $T_{o}$ is the initial value of $T_{c}$ $\left(503{ }^{\circ} \mathrm{C}\right)$. Although additional experiments must be performed at other temperatures, it seems to be clear that the measurement of $T_{c}$ may be used to detect and quantify the effects of the $475^{\circ} \mathrm{C}$ embrittlement on the mechanical properties of DSS. It is important to be sure, however, that the heating rate applied in the TMA is the same for all conditions investigated.

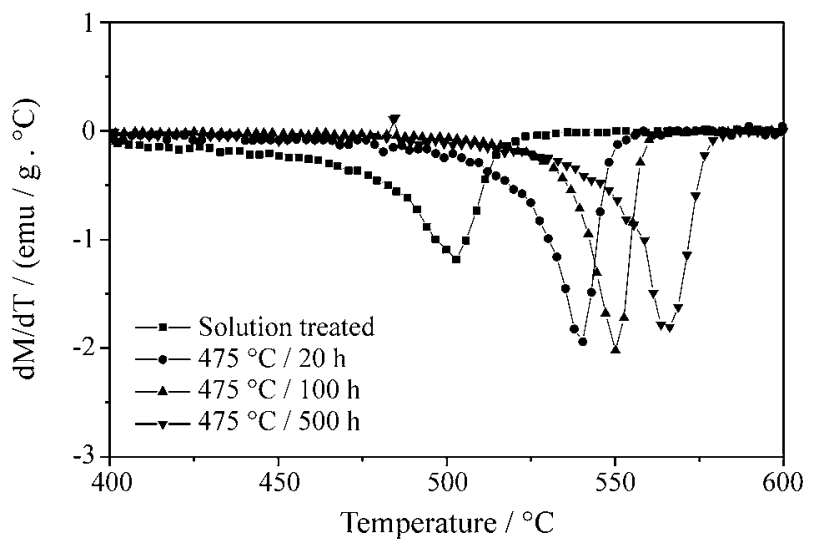

Figure 5. Curie Temperature $\left(\mathrm{T}_{\mathrm{c}}\right)$ determination.

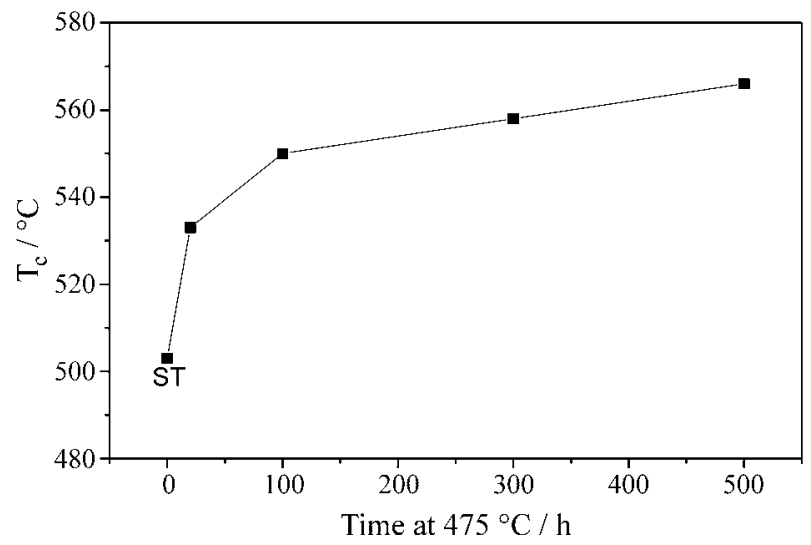

Figure 6. $\mathrm{T}_{\mathrm{c}}$ dependence on the time of exposure at $475^{\circ} \mathrm{C}$. 


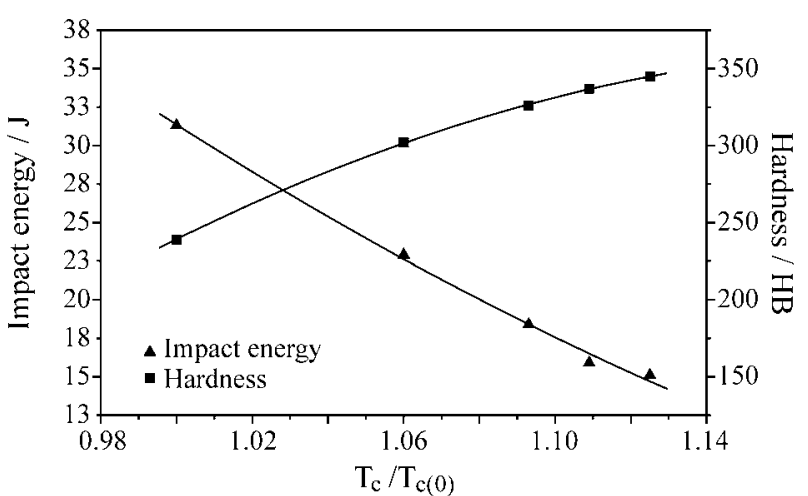

Figure 7. Mechanical properties (impact energy and Brinnel hardness) against $\mathrm{T}_{\mathrm{c}}$.

\section{Conclusions}

The studied duplex stainless steel UNS S31803 undergoes a reasonable hardening and embrittlement in the first $100 \mathrm{~h}$ of ageing, but is only after $500 \mathrm{~h}$ that its corrosion resistance to the $10 \% \mathrm{HNO}_{3}+0.05 \% \mathrm{HF}$ solution is deteriorated.

It was found that in ageing times up to $500 \mathrm{~h}$ the magnetic properties $B_{r}$ and $B_{s}$ remained nearly unaltered and the coercive force $\left(\mathrm{MH}_{\mathrm{c}}\right)$ presented a slight increase with the ageing time. There was no significant difference in the hysteresis loops of the sample unaged and the one aged at $475^{\circ} \mathrm{C}$ for $500 \mathrm{~h}$. On the other hand, the magnetic transition temperature (Curie temperature, $\mathrm{T}_{\mathrm{c}}$ ), measured by thermomagnetic analysis, increased with ageing time. This is due to the progressive reduction of $\mathrm{Cr}$ content in the Fe-rich phase during the ageing process. This phenomenon may be used to detect and quantify the effects of the $\alpha$ 'precipitation in duplex stainless steels.

\section{References}

1. Krull, P.; Pries, H.; Wohlfahrt, H.; Tosch, J. Welding Research Abroad, v. 44, p. 2, 1998.

2. Olsson, J.; Leffler, B.; Jorgensen, C. In: Proceedings of $9^{\text {th }}$ International Symposium on Corrosion in the Pulp and Paper Industry, p. 161, Montreal/Canada, May, 1996.
3. Tersmeden, K. Process Safety Progress, v. 16, p. 110, 1997.

4. Charles, J. La Metallurgia Italiana, v. 87, n. 2, p. 83, 1995.

5. Massoud, J.P.; Auger, P.; Danoix, F.; Rezakhanlou, R.; Van Duysen, J.C. In: Proceedings of the $6^{\text {th }}$ International Symposium on Environmental Degradation of Materials in Nuclear Power Systems-Water Reactors, San Diego (CA)/USA, p. 399-407, 1993.

6. Llanes, L.; Mateo, A.; Violan, P.; Méndez, J.; Angada, M. Materials Science and Engineering A, v. 234-236, p. 850, 1997.

7. Maeda, N.; Goto, T.; Nakamura, T.; Naito, T.; Kumano, S.; Nakao, Y. Int. J. Pres. Ves. \& Piping, v. 71, p. 7, 1997.

8. Solomon, H.D.; Koch, E.F. Scripta Metallurgica, v. 13, p. $971,1979$.

9. Tsuchiya, S.; Ishikawa, Y.; Ohtaka, M.; Yoshimura, T. JSME International Journal Series A, v. 38, p. 384, 1995.

10. Evanson, S.; Otaka, M.; Hasegawa, K. J. Engineering Mater. and Technology, v. 114, p. 42, 1992.

11. Kim, S.; Jae, W.; Kim, Y. Journal of the Korean Nuclear Society, v. 29, p. 361, 1997.

12. Annual Book of ASTM Standards, Designation E-2394b, p. 137, 1995.

13. Chikazumi, S. Physics of Magnetism, Ed. John Willey and Sons, 1964.

14. Cullity, B.D. Introduction to Magnetic Materials, Ed. Addison Weley Publishing Company, EUA, 1972.

15. Yi, Y.S.; Shoji, T. Journal of Nuclear Materials, v. 240, p. 62, 1996.

16. Sang, J.; Yoon, Y.K. Scripta Met. Materiallia, v. 32, p. $1163,1995$.

17. Solomon, H.D.; Levinson, L.M. Acta Metallurgica, v. 26, p. 429, 1978.

18. Bozorth, R.M. Ferromagnetism, Van Norstrand, D., ed., Company, USA, 1964. 